\title{
PW01-037 - Amyloidosis probability depending on MEFV type
}

\author{
A Simonyan ${ }^{*}$, A Ayvazyan ${ }^{1}$, V Vardanyan ${ }^{1}$, L Kozlovskaya², V Rameev² \\ From 7th Congress of International Society of Systemic Auto-Inflammatory Diseases (ISSAID) \\ Lausanne, Switerland. 22-26 May 2013
}

\section{Introduction}

Familial Mediterranean fever (FMF) is a hereditary inflammatory disorder. FMF is an autoinflammatory disease caused by mutations in MEFV, a gene which encodes a 781 -amino acid protein denoted pyrin. AA-amyloidosis is the main complication of FMF.

\section{Objectives}

To access the relationship between MEFV genotype and occurrence of amyloidosis in patients with Familial Mediterranean Fever (FMF).

\section{Methods}

69 FMF patients (37 with amyloidosis, 32 - without amyloidosis) were investigated. All 69 patient underwent molecular-genetic investigation (PCR method), 9 different mutant combinations of MEFV gene were detected: 3 homozygous - M694V/M694V(AA) in 25 patients, M680I/ $\mathrm{M} 680 \mathrm{I}(\mathrm{CC})$ - in 4, V726A/V726A(BB) in 1, 5 compound heterozygous - M694V/V726A(AB) in 17, M694V/M680I (AC) in 9, V726A/M680I(BC) in 5, V726A/R761H(BD) in $1, \mathrm{M} 680 \mathrm{I} / \mathrm{R} 761 \mathrm{H}(\mathrm{CD})$ in 1 , and 1 heterozygous - M694V/ $\mathrm{U}(\mathrm{AU})$ in 6 patients.

\section{Results}

3 of 9 detected MEFV genotypes (V726A/V726A, V726A/ $\mathrm{R} 761 \mathrm{H}$ и $\mathrm{M} 680 \mathrm{I} / \mathrm{R} 761 \mathrm{H}$ ) were not revealed in FMF patients with amyloidosis, but in the present investigated group these genotypes were sporadic (3 patients), so that it's not possible to decline the probability of amyloidosis development in these genotypes unambiguously. The rest 6 genotypes (M694V/M694V, M694V/U, M694V/M680I, M694V/V726A, V726A/M680I, M680I/M680I) were found either in patients with amyloidosis or without. Particularly M694V-genotypes were distributed approximately equally among 2 subgroups of patients. M694V/M694Vgenotype appeared to be more frequent in patients with amyloidosis - in 17 of 37 patients $(45,9 \%)$ in comparison with patients without amyloidosis - in 8 of 32 patients (25\%). Nevertheless, detected difference proved to be non-significant $\left(\chi^{2}=12,51171, \mathrm{p}=0,12981\right)$.

\section{Conclusion}

Our investigation hadn't revealed significant relationship between carriage of definite FMF genotype and development of amyloidosis. The absence of genetic relationship between FMF and amyloidosis may be explained by the fact that MEFV and SAA genes are located on different chromosomes -16 and 11 respectively, and the carriage of the mentioned genes has unlinked character.

\section{Disclosure of interest}

None declared.

\section{Authors' details}

${ }^{1}$ yerevan State Medical University, Yerevan, Armenia. ${ }^{2}$ Moscow Medical Academy after I.M. Sechenov, Moscow, Russian Federation.

Published: 8 November 2013

doi:10.1186/1546-0096-11-S1-A90

Cite this article as: Simonyan et al:: PW01-037 - Amyloidosis probability depending on MEFV type. Pediatric Rheumatology 2013 11(Suppl 1):A90.

1yerevan State Medical University, Yerevan, Armenia

Full list of author information is available at the end of the article 